\title{
Making Visible New Learning: Professional Development with Open Digital Badge Pathways
}

\author{
Erin Fields \\ Liaison Librarian and Flexible Learning Coordinator \\ Humanities \& Social Sciences Division \\ University of British Columbia \\ erin.fields@ubc.ca
}

\begin{abstract}
Emerging fields of study and technological developments have provided the library profession with new opportunities to shift the role of the library and librarian. This shift, while exciting for its possibilities, complicates professional development when an attempt is made to build expertise in areas without structured learning paths as found in formalized education. This article addresses possible ways the profession can give clarity and purpose to our own educational and career growth while building a collaborative and diverse learning program through open digital badges.
\end{abstract}

\section{Keywords}

professional development; library education; learning pathways; open digital badges

\section{Introduction}

The importance of lifelong learning in librarianship becomes more evident each year as new areas of expertise continue to change the profession. Blakiston, in her article on continual learning and library organizational culture, states, "Job descriptions throughout the library organization will likely look very different in just five years' time, and the pressure to keep up and stay relevant is greater than ever" (729). This has proven true. To remain relevant, the profession must adapt quickly; to adapt, learning opportunities in new competencies must be made visible. However, professional development proves complicated in an environment where emerging competencies are hard to articulate, where opportunities are too numerous to strategize a clear course of learning, and where learning pathways that illustrate focused professional growth remain unstructured and independent of guidance from the field. This article addresses the many barriers librarianship has with professional development outside of formalized education environments. It discusses how emerging educational technologies in the form of open digital badges (ODB) could provide new approaches to professional development that can be articulated with evidence and endorsed by the profession.

\section{Competencies in Librarianship}

Maintaining relevancy in the face of shifting community needs is a foremost challenge for libraries. These changing needs, while offering new opportunities, also raise 
challenges for the education and development of library professionals. At a recent American Library Association (ALA) summit on the future of libraries, an identified barrier for fully realizing the library of the future was "...the education and training of library staff and identification of the skillset that librarians will need in the future" (Bolt 13). Why would education and identification of competencies for library professionals be identified as a major barrier to the future vision of the library? As noted by the International Federation of Library Associations (IFLA) report titled "Continuing Professional Development: Principles and Best Practices," the "...constant flux in the needs of societies, changing technologies, and growth in professional knowledge demand that information workers must expand their understanding and update their skills on an ongoing basis." However, identifying competencies, knowledge, and skillsets when the needs of society are moving targets is problematic. Additionally, while the competencies themselves may be hard to identify, the environment in which the knowledge, skills, and behaviours are to be demonstrated also impacts the type of expertise needed.

Core knowledge and skillsets cannot be independent of the context in which they will be practiced. Socio-cultural, geographic, economic, and technological divides with the communities being served will affect the competencies needed and used. Rehman states, "These factors make it clear that when we are trying to configure competencies in a particular setting, we need to articulate contextual peculiarities" (71). In response, professional knowledge and skills needs to be developed in collaboration with institutions and organizations governing librarianship and the larger public that will interact with and guide the library toward its future (Khalid 14).

The employment market also affects competency development in library education (Kennan et al. 187; Macpherson 12). However, clearly identifying the needs of the market is not an easy task. As Chow et al. state, "... the employment perspective is highly variable and eclectic, leading to a vague set of skills employers seem to value" (4). While core competencies are developed within the profession, the responsiveness of these competencies to market needs is not simple. There are no agreed-upon competencies among employers. Additionally, identifying the market needs would require a large-scale analysis of employment opportunities, employer expectations, and employee needs, among other variables (Rehman 78).

While certain competencies might be identifiable across professional associations, educational institutions, and contextual spaces (e.g. local markets, community needs, etc.), the integration of the identified competencies into a formalized education strategy is complicated by the need for expertise that may not have fully developed within the field. Emerging trends provide opportunities for libraries to evolve and become central forces for change. However, incorporating these trends into official curricula is difficult, as program modification to address new competencies is constrained by the process of credit approval in higher education. Additionally, as Rehman states, "...faculty members do not have the competence in all areas in which you wish to develop new curriculum" (78). While the desire to integrate new knowledge and skills into the education of emerging professionals exists, the ability to follow through with this may be beyond the educators' and library communities' expertise. If formal education suffers trying to 
incorporate new trends into curricula, growing a professional development program that can identify experts to guide skills training will be difficult.

\section{Learning Pathways in Library Professional Development}

Learning pathways, defined as the route an individual takes to acquire new learning, are based on the choices of the learner. In interviews performed by the Centre for Research in Education, Equity and Work (CREEW) on learning pathways and vocational training, adult learners described their own learning pathways as “...'stepping stones', 'zigzags' and 'crooked paths"' (Harris, Rainey, and Sumner 11). The metaphor of the unstructured path was in part based on how learning would veer off in unexpected directions in mid-pursuit of a learning goal. The circuity of their path was due to a lack of guidance, lack of appropriate previous knowledge, and inexperience in the educational process. Without a clear direction, "....participants acknowledge mistakes and the inefficiency in their pathways - that there might have been an easier or quicker ways to get to where they were..." (Harris, Rainey, and Sumner 39).

Professional development in librarianship is often dependent on individuals identifying trends and opportunities. For librarianship, there is no lack of learning opportunities. Opportunities range from traditional education (e.g. degree programs, additional qualification courses), to professional development (e.g. conferences, professional association events, workshops, and lectures), to the daily activities of working in a complex environment that requires diverse knowledge, abilities, and problem solving approaches. While the CREEW report focuses on "facilitated learning pathways" through accredited vocational training and supports, it isn't difficult to identify how online open learning would further complicate the path (Harris, Rainey, and Sumner 9). With the influx of open education resources, information professionals can expand their understanding on a topic without being physically present at the learning event. Video lectures, podcasts, and interactive websites are just a few ways by which traditional education models can be supplemented, or in some cases replaced. However, the high number of online learning opportunities available to professionals can make strategic selection difficult. Additionally, when new areas emerge in a profession that is constantly shifting, developing a plan around learning activities becomes more difficult. Clearly articulating a learning plan in this environment makes discussions on career progress nearly impossible.

\section{Open Digital Badges-An Overview of Possibilities}

With the introduction of open digital badges (ODB) as a form of credentialed learning, an organized collaborative approach to professional development may be possible. Developing badges approved and sponsored by our community and spanning libraries, library programs, and organizations, could provide an opportunity to guide our own learning in emerging areas, to grow our own skills and knowledge directly applicable to local contexts, and to recognize abilities exhibited in work, school environments, and professional bodies that may otherwise be complex to illustrate. 
Before discussing the possibilities that ODBs could provide to learning pathways and professional growth in librarianship, we need to answer: 1) What are ODBs; 2) How can ODB paths provide visibility and structure to learning pathways; 3 ) How can the ODB collaborative model be applied to develop new competencies in librarianship; 4) How can ODBs benefit local contexts and the immediate needs of a changing profession?

(Fig. A) Open Badges Napkin Sketch. Chris Appleton (Mozilla Foundation). Licensed under a CC Attribution 4.0 International License.

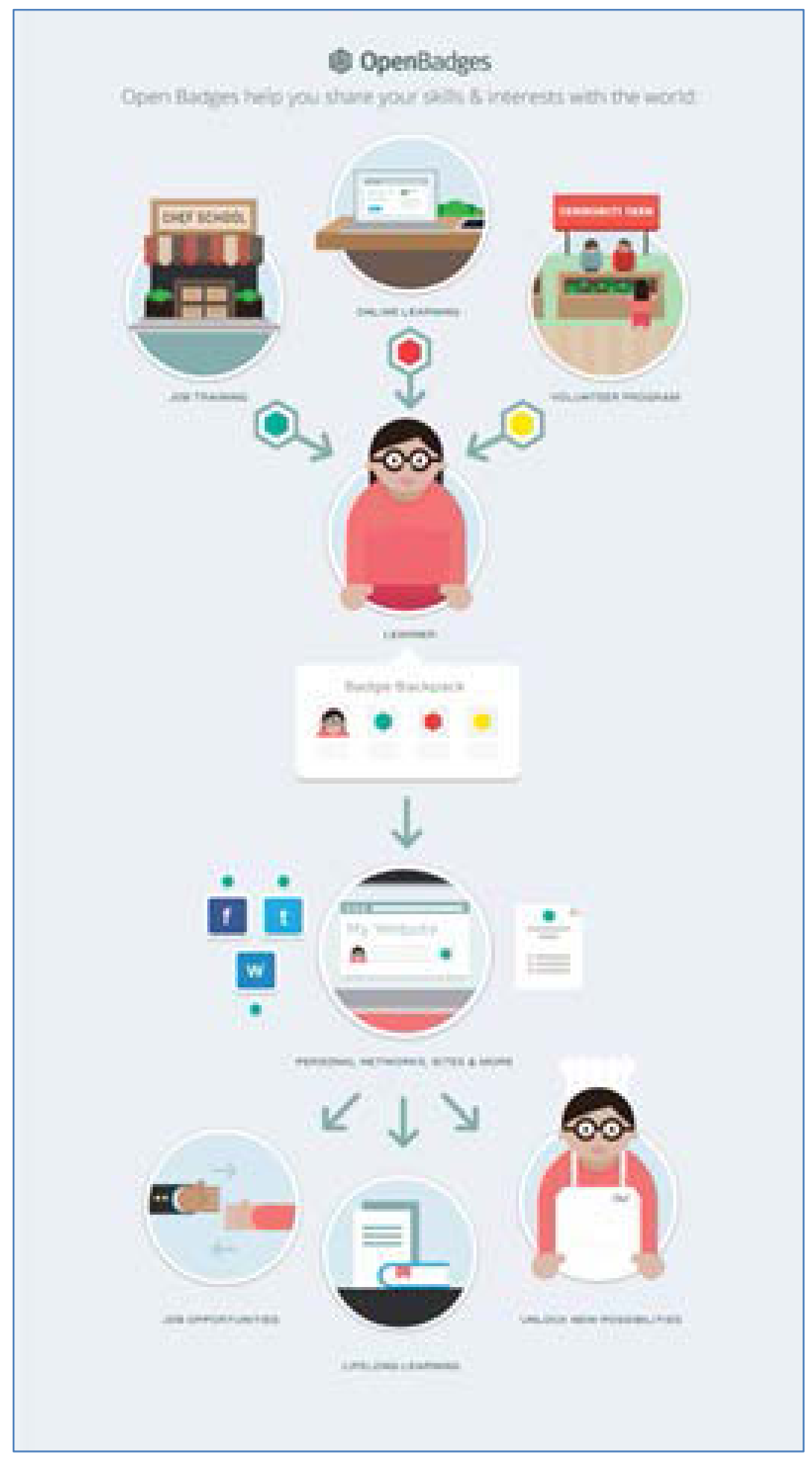




\section{Open Digital Badges Defined}

An ODB is a digital signifier of accomplishments, skills, qualities, or experiences. The signifiers have embedded metadata that includes the issuing organization, criteria for earning the badge, and evidence of the skill or knowledge acquired. The portability of the badges allows badge earners to publicly share all learning experiences, whether acquired from formal or informal education settings, to social media sites like Linkedln and Facebook (Open Badges UBC).

\section{Open Digital Badge Pathways}

While ODBs provide the ability to credential learning, structuring the pathway can provide clarity and visibility to learning activities. Completion of online webinars, MOOCs, and engagement in organizations are all examples of learning opportunities in librarianship that may go unnoticed on a professional development track. As these opportunities provide limited certification of learning and the skills are often difficult to assess (e.g. organization, critical evaluation, interpersonal communication, etc.), badge paths can highlight activity and engagement from distributed learning opportunities.

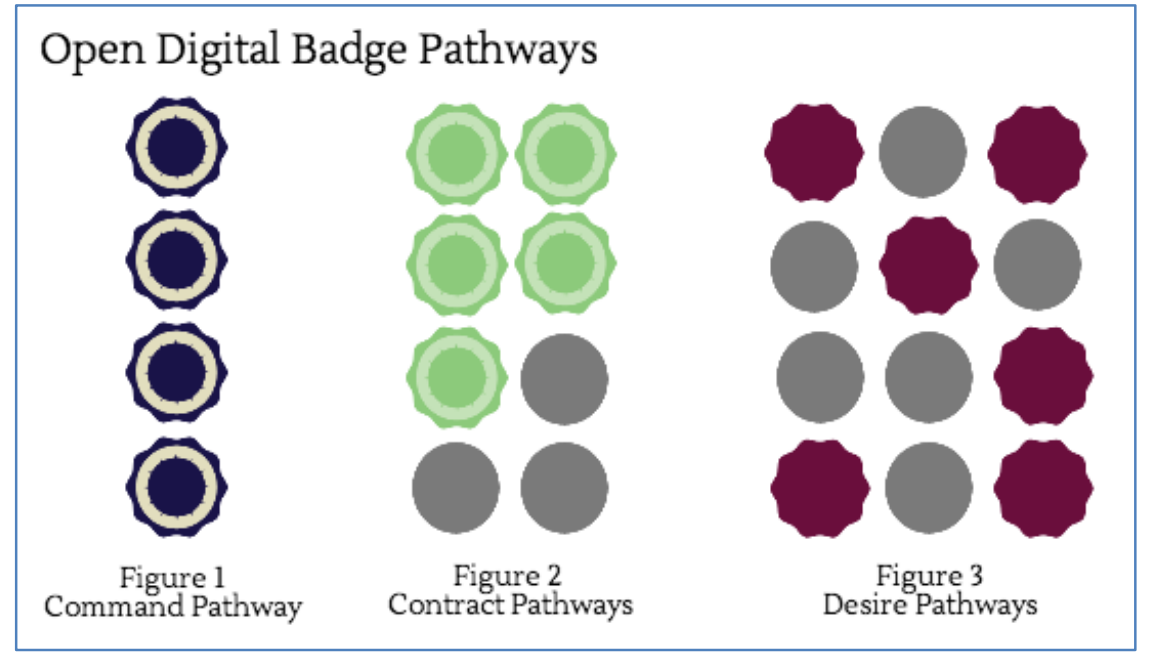

(Fig. B) Open Digital Badge Pathways

ODB paths are fundamental to the development of a badging system. These pathways can be as prescriptive or open as the designer chooses. Figure 1 illustrates the most prescriptive pathway, the command pathway, where a learner must go through a linear earning process to earn badges. An example of a command pathway is the leveled badge system under development by the Young Adult Library Services Association (YALSA). This command pathway is based on the core competencies outlined in the Competencies for Serving Youth in Libraries. Figure 2 illustrates the contract pathway, which, while linear in its structure, allows the learner to select a pathway and determine how far they will go in the learning process. An example of the contract pathway is the Edmonton Public Library's Summer Reading Program. This badge system offers maker badges for use of arduinos, 3D models, and digital art creation. While all badges relate to one another thematically, each badge can be earned independently of the others 
(EPL). Finally, Figure 3 illustrates the desire pathway, which has no designed pathway, and earning badges is based on the learner's interests (Casilli).

A linear pathway provides structured learning across disparate opportunities and can provide visibility to learner competencies and, eventually, to expertise in particular areas. Carla Casilli, Mozilla's Director of Badge System Design + Implementation, states,

All badge earners leave behind a trail. That badge trail may prove to represent merely a series of required steps; that path may illustrate a series of revealing, personally inspired choices, or that path may appear to be erratic and nonsensical, indicating nothing. But rarely is that last example the case.

The badge pathway allows a learner to develop a narrative around his or her own learning. As Casilli notes, this builds personal value for the learner while externally promoting his or her learning goals and proficiencies.

\section{Benefits of Open Digital Badges}

The American Institute for Research (AIR) report, titled "The Potential and Value of Using Digital Badges for Adult Learners," outlines how badges can benefit more than the earner. Badges are valuable for issuers, who can provide credentialing without accreditation through a formal education system (Finkelstein, Knight and Manning 3). As noted earlier, curriculum modifications for librarianship cannot occur quickly enough to address emerging needs within the profession, and at times the initial expertise for these areas lies outside of the field. As ODBs remain open and outside of the bureaucracy of formal education, the development of an authoritative credential based on the immediate needs of the profession and workplace is possible. Finkelstein, Knight, and Manning write,

... granting credit through badges can level the playing field and thus make it easier for local community groups, learning program providers, and training programs to offer opportunities to earn badges that meet national or associationbased standards (12).

While masters and library technician programs can grant the library and information science degree or diploma, a badging program could connect that learning to specific professional standards (e.g. ACRL Guidelines and Standards, YALSA Competencies, etc.) and emerging employment needs requiring leadership (e.g. data management, open education, etc.). This would extend the professional development within specific contexts, encourage lifelong learning, and provide associations and employers with a larger role in the continuing education of the profession. 


\section{Sample Open Digital Badge Collaboration for Librarianship}

Table 1 provides a possible ODB collaboration focusing on computer programming skills and emerging needs in libraries.

(Table 1) Sample Digital Badge Collaboration

\begin{tabular}{|c|c|}
\hline Table 1 & $\begin{array}{l}\text { Sample Open Digital Badge Collaboration } \\
\text { Emerging Technologies in Libraries }\end{array}$ \\
\hline Partners & $\begin{array}{l}\text { Library Degree Program } \\
\text { Canadian Association of Research Libraries (CARL) } \\
\text { Codeacademy }\end{array}$ \\
\hline Competencies & $\begin{array}{l}\text { Understanding of the principles of web page design, } \\
\text { maintenance, and development (as identified by the Core } \\
\text { Competencies for } 21 \text { st Century CARL Librarians (2013) } \\
\text { document and the core information technology course in the } \\
\text { Library Degree Program) }\end{array}$ \\
\hline Learning Pathway & $\begin{array}{l}\text { Successful completion of the HTML and CSS tutorials from } \\
\text { Codeacademy. } \\
\text { Successful completion of Library Degree Program coursework } \\
\text { and assignment on web design principles. }\end{array}$ \\
\hline \multirow[t]{4}{*}{ Badge Accredited } & $\begin{array}{l}\text { Description - This badge is issued as proof of understanding of } \\
\text { basic HTML, CSS, and web design principles in a library } \\
\text { context. }\end{array}$ \\
\hline & $\begin{array}{l}\text { Criteria - Completion of the HTML and CSS tutorials from } \\
\text { Codeacademy; successful completion of Library Degree } \\
\text { Program coursework and assignment on web design } \\
\text { principles. }\end{array}$ \\
\hline & Issuer - CARL, Library Degree Program, Codeacademy \\
\hline & $\begin{array}{l}\text { Evidence - http:XXXX (A website coded in HTLM and CSS, } \\
\text { incorporating web design principles) }\end{array}$ \\
\hline
\end{tabular}

In this example, the partners, competencies, learning pathway, and accredited badge, including the badge metadata, are outlined. Potential partners are drawn from both the internal library community and the external community, but all are focused on a common goal which, for this example, is skill development in web design and coding. The partners include CARL, a library degree program, and Codeacademy, a free 
interactive platform that focuses on the development of programming skills including

"...core programming concepts and syntax for the world's most popular languages..." (Codeacademy) such as HTML, CSS, Python, PHP, JavaScript, and Ruby.

\section{Current Opportunities to Earn Open Digital Badges}

There are numerous opportunities to earn ODBs in competencies relevant to the library profession. While the more integrated and collaborative opportunities that ODBs could provide to librarianship are not yet a reality, badges in areas like emerging technologies and open education can already be a part of professional development strategies.

The following list provides a sampling of badge-earning opportunities:

- Badge 101 from Mozilla (http://openbadges.org/earn/). Learn the basics of what a badge is and how it can be used in a variety of contexts. Mozilla also lists additional badge-earning opportunities.

- Digital Me (http://www.digitalme.co.uk/). Digital Me lists a variety of badging venues, including social media, digital entrepreneurship, and digital badge design.

- Codeschool (https://www.codeschool.com/). Learn a variety of coding languages (e.g. Java, PHP, CMS) through online interactive tutorials.

- Peer 2 Peer University (http://badges.p2pu.org/en/). Peer 2 Peer University, in addition to listing badge-earning opportunities from a variety of partners, provides a platform to develop badge-based projects.

\section{Conclusion}

ODBs are a relatively new form of educational technology. What they will become is difficult to say; however, the growth of badges as a form of credential will need the dedication and commitment of various partners. If partnerships between library programs, associations, library systems, and external interested partners were developed, ODB systems could begin to articulate future roles for librarians by identifying areas of learning for both established librarians and new graduates. A cohesive learning narrative developed through structured badge paths would provide a level of clarity currently lacking in professional development. In partnering with library programs, ODBs could make skill acquisition more visible by providing concrete samples of accomplishment through their attached metadata. Finally, through collaborative endorsement by external and internal organizations and library systems, the badge accomplishment could be recognized in the hiring and promotion process for its focus on local needs and contexts. 


\section{Works Cited}

"Badges for Learning." Young Adult Library Services Association. American Library Association, n.d. Web. 8 Feb. 2015.

Blakiston, Rebecca. "Building Knowledge, Skills, and Abilities: Continual Learning in the New Information Landscape." Journal of Library Administration 51.7-8 (2011): 728-43.

Bohannan, April. "Library Education: Struggling to Meet the Needs of the Profession." Journal of Academic Librarianship 17.4 (1991): 216-19.

Bolt, Nancy. "Libraries from Now On: Imagining the Future of Libraries ALA Summit on the Future of Libraries-Report to ALA Membership." American Library Association, May 20, 2014. Web. 8 Feb. 2015.

Canadian Association of Research Libraries. "Core Competencies for 21st Century CARL Librarians." Canadian Association of Research Libraries, Oct. 2010. Web. 8 Feb. 2015.

Casilli, Carla. "Badge Pathways - Part 2." Persona. Wordpress.com. n.d. Web. 8 Feb. 2015.

Codeacademy. Learn to Code, Codeacademy, 2015. Web. 8 Feb. 2015.

Edmonton Public Library. Summer Reading Program, Edmonton Public Library, 2014.Web. 8 Feb. 2015.

Finkelstein, Jonathan, Erin Knight, and Susan Manning. "The Potential and Value of Using Digital Badges for Adult Learners." American Institute for Research, 2013. Web. 8 Feb. 2015.

Harris, Roger, Linda Rainey, and Robert Sumner. "Paving or Stepping Stones? Learning Pathways Within and Between Vocational Education and Training and Higher Education." Centre for Research in Education, Equity and Work, 2006. Web. 8 Feb. 2015.

Kennan, Mary Anne, et al. "Changing Workplace Demands: What Job Ads Tell Us." Aslib Proceedings 58.3 (2006): 179-96.

Khalid, Hafiz M. "The Role of Specialized Knowledge for the Development of Professional Development Competency-the Case of LIS." Pakistan Library \& Information Science Journal 42.2 (2011): 13-16.

MacPherson, Meredith A. "Alternative Careers for Graduates of Library Science Programs: Are Library Schools Doing Enough?" MS Thesis. U of North Carolina at Chapel Hill, 2008. Web. 8 Feb. 2015. 
Rehman, Sajjad. "Developing New Competencies among LIS Professionals: Challenges for Educators." Pakistan Journal of Library \& Information Science (PJLIS) 9 (2008): 67-81. Web. 8 Feb. 2015.

Surman, Tonya, and Mark Surman. "Listening to the Stars: The Constellation Model of Collaborative Social Change." Social Space (2008): 24-29. Web. 8 Feb. 2015.

"What are Open Badges?" Open Badges UBC. n.d. Web. 8 Feb. 2015.

Young Adult Library Services Association. "Badges for Learning: Competencies for Serving Youth in Libraries." American Library Association. Feb. 2014. Web. 8 Feb. 2015. 